\title{
Power system voltage instability risk mitigation via emergency demand response-based whale optimization algorithm
}

\author{
Mohammed Amroune ${ }^{1 *}$, Tarek Bouktir ${ }^{1}$ and Ismail Musirin ${ }^{2}$
}

\begin{abstract}
In recent years, due to the economic and environmental issues, modern power systems often operate proximately to the technical restraints enlarging the probable level of instability risks. Hence, efficient methods for voltage instability prevention are of great importance to power system companies to avoid the risk of large blackouts. In this paper, an event-driven emergency demand response (EEDR) strategy based on whale optimization algorithm (WOA) is proposed to effectively improve system voltage stability. The main objective of the proposed EEDR approach is to maintain voltage stability margin (VSM) in an acceptable range during emergency situations by driving the operating condition of the power system away from the insecure points. The optimal locations and amounts of load reductions have been determined using WOA algorithm. To test the feasibility and the efficiency of the proposed method, simulation studies are carried out on the IEEE 14-bus and real Algerian 114-bus power systems.
\end{abstract}

Keywords: Voltage stability, Emergency demand response, Whale optimization algorithm, Blackouts

\section{Introduction}

In recent years, serious power grid blackouts have occurred throughout the world bringing with them important economic losses and affect the lives of residents. Voltage instability incidents have been identified as contributing factors in several recent worldwide blackouts [1]. Therefore, developing efficient countermeasure techniques for the prevention of voltage collapses has attracted important aspects of power system companies and researchers. Over the past years, several emergency controls have been adopted to protect the system against voltage collapses. Adjustment of Load Tap Changer (LTC) transformer taps is the well-known emergency action for containing voltage instability. Different emergency schemes may be applied using the LTCs. One of the popular forms of emergency actions using LTCs is

\footnotetext{
* Correspondence: mohammed.amroune@yahoo.fr

${ }^{1}$ Department of Electrical Engineering, University of Ferhat Abbas Setif 1,

19000 Setif, Algeria

Full list of author information is available at the end of the article
}

tap blocking, which is an indirect way of load reduction [2]. Otomega et al. [3] proposed an LTC control logic strategy that can be used in emergency voltage conditions. The principle of the proposed tap-reversing strategy is to inverse the tap actions once the power system voltages fall below some threshold. Vournas and Karystianos [4] discussed how tap-blocking and tap-reversing based LTC techniques can avoid an approaching voltage collapse, as well as the advantages and drawbacks of these techniques. Another type of LTCs was the voltage set-point reduction, which is based on the lowering of the reference voltage to improve voltage stability [5].

The generation rescheduling was another technique to prevent voltage collapse. Several approaches reported in the literature concerning the implementation of generation rescheduling to avoid voltage instability of a power system [6-15]. Load shedding (LS) technique was also identified as an effective emergency action against voltage collapse because it results in an instantaneous voltage stability enhancement. However, due to the 


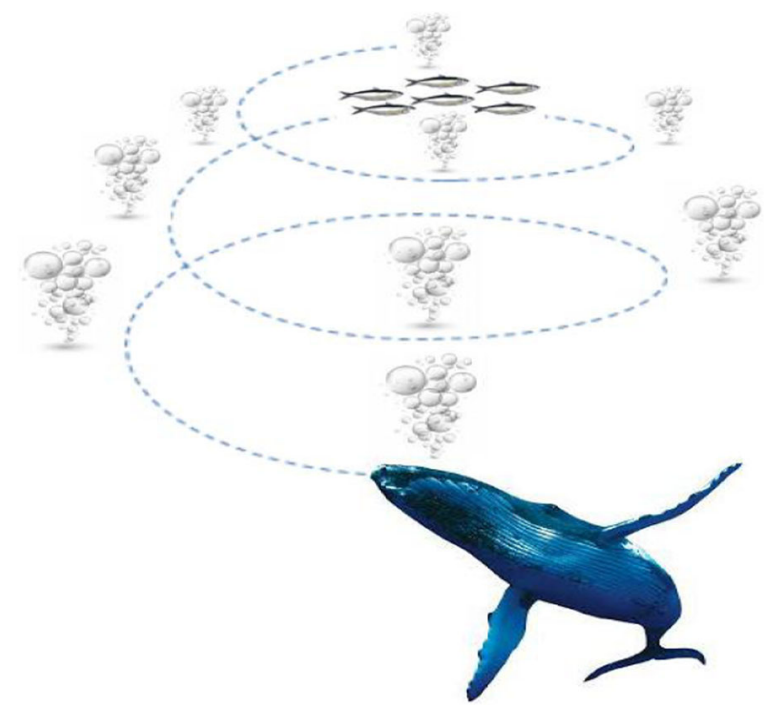

Fig. 1 Humpback whales bubble-net feeding technique

disturbance affected the consumers that have been shed; this action must be the latest protection applied method. LS techniques are generally divided into three main types i.e., conventional, adaptive and computational intelligence-based LS [16]. Conventional load shedding techniques are of two types under frequency load shedding (UFLS) and under-voltage load shedding (UVLS). UFLS involve shedding determined amounts of the load if the system frequency falls below its specified range [16]. In the same manner, UVLS is applied by power utilities to avoid a risk of voltage collapse and restore voltage to its nominal value [17]. The major drawback of the conventional LS techniques is that are limited by

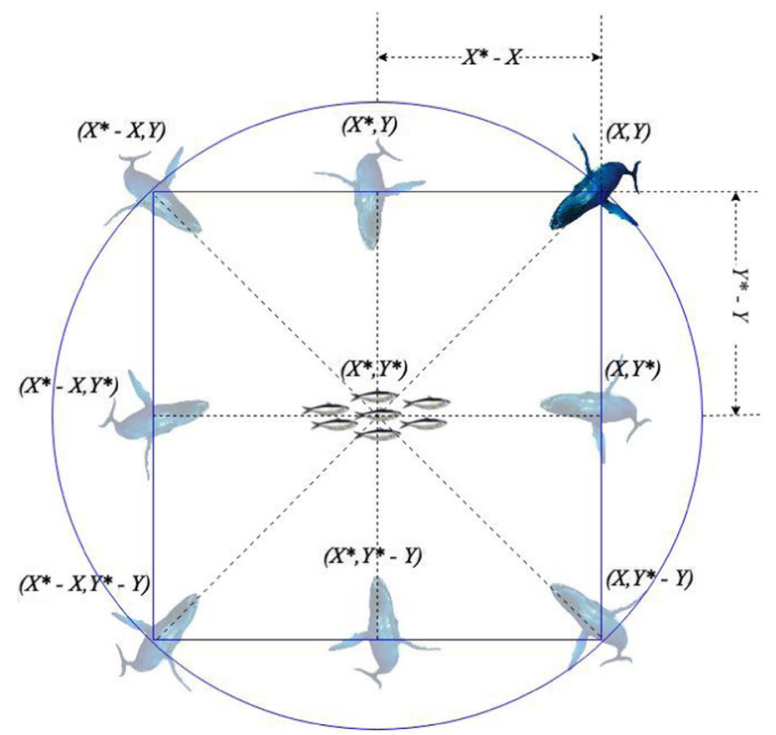

Fig. 2 The principle of prey encircling technique used by humpback whales their incapability to deliver optimum LS [18]. Adaptive LS is another type of LS techniques. It is based on the use of a power swing equation to shed the desired amount of load as reported in [19]. Albeit the Adaptive LS techniques improve the reliability of conventional LS, they suffer from un-optimum LS due to the variations in the rate of change of frequency.

The application of computational intelligence techniques was another alternative for solving LS problem. The benefits of the application of computational intelligence in LS over the conventional ones are outlined in [16]. The ANN [20, 21], Adaptive neuro-fuzzy inference system (ANFIS) [22, 23] and decision tree technique [24] were applied to shed load of the power system. Meta-heuristic optimization algorithms have some applications in LS problem. Among the implemented meta-heuristic methods to minimize the LS, GA-based method [25], differential evolution (DE) algorithm [26], glowworm swarm optimization (GSO) algorithm [27], harmony search algorithm (HSA) [28], PSO algorithm [29] and PSO-simulating annulling (PSO SA) optimization technique [30].

In recent years, under the paradigm of the smart grid, in which the major operations are executed in a coordinated and efficient manner, the focus for solving power system problems has moved more from the supply-side to the demand-side. Such concept is known as demand response (DR), which the main purpose is the adjustment of consumer demand to increase efficiency and reliability of the power system [31]. Emergency demand response (EDR) is one of the most widely used DR programs. It is called upon when power generation is anticipated to experience a shortfall or during the contingency situations [32]. In EDR programs, the EDR participants are contractually obligated to provide a set amount of capacity and they receive payments for being available and face financial penalties for non-attendance. Several works are reported in the literature on the implementation of EDR programs [33-39]. However, the application of such programs to improve the power system security has not been completely addressed. The only work -as far as the author knows- discussed the use of EDR in power system security enhancement is that of Wang et al. [40]. In this work, an event-driven EDR strategy is proposed to improve the operating reserves of the power system under credible contingencies. A multistage optimization technique based on segmentation of the original nonlinear problem, associated with EDR program, into a series of linear optimization problems is proposed. However, this procedure needs to be repeated several times until a required security margin is achieved, which is a time-consuming task. Another disadvantage of the proposed strategy is that it considers all loads in the system as EDR participants which results in 


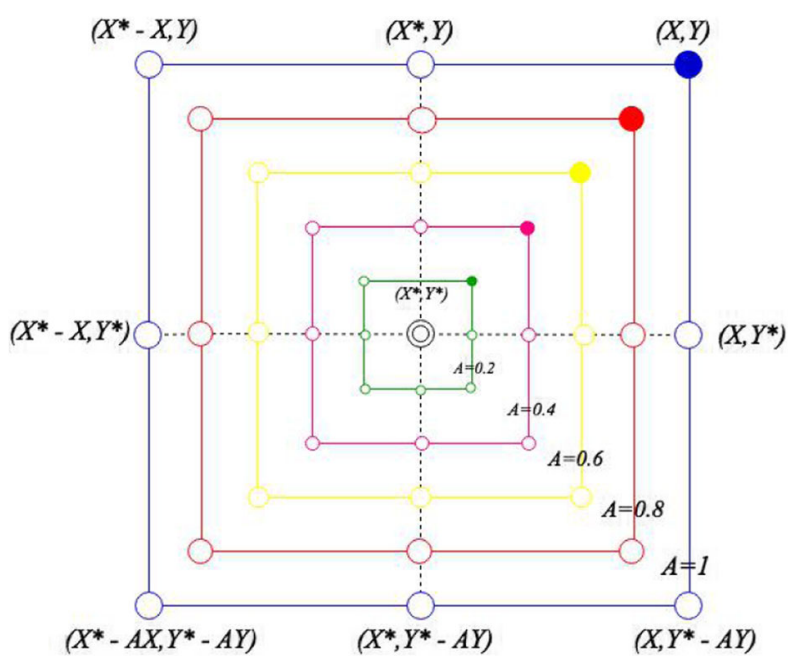

Fig. 3 Shrinking encircling technique

a high cost of implementation of such programs. Thus this paper uses the recently developed optimization algorithm named whale optimization algorithm (WOA) to compute the required load reduction, during emergency conditions, and then distribute this amount, optimally, between customers participating in the EDR program. Consequently, some important contributions of this work can be listed as follows:

- Development of an Event-driven Emergency Demand Response (EEDR) approach based WOA optimization algorithm to avoid a risk of large blackouts during emergency situations.

- Application of WOA as a robust optimization method to find the appropriate EEDR participants.

- Consideration of voltage stability margin in the proposed EEDR strategy.

The proposed approach is investigated on IEEE 14-bus and real Algerian 114-bus power systems showing

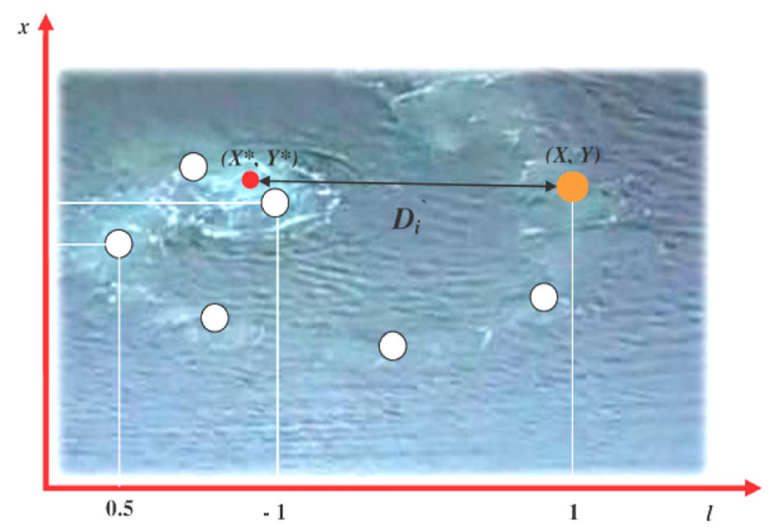

Fig. 4 Spiral updating position promising results and proving their practical efficiency to ensure system stability under critical situations.

\section{Problem formulation}

One of the serious challenges for power systems is to maintain stable operations, especially during emergency situations. Event-driven based Emergency Demand Response (EEDR) program is one of the solutions that used when the security of power systems is at risk. To implement such programs, the following problems need to be solved: (i) The selection of the appropriate EEDR participants. (ii) For each serious event, the optimal amount of the demand reduction of each participant must be found in order to minimize the total cost.

\subsection{Selection of load buses for EEDR program}

The selection of load buses for EEDR involves the determination of the suitable locations for load reduction. An effective way to find suitable locations is to identify the load buses having a higher impact on voltage stability. This can be mathematically formulated as a non-linear constrained optimization problem, where the main goal is the determination of the optimal location for reactive power support. Accordingly, the objective function can be defined as below:

$$
\min \left(F_{c}+\lambda_{P} P_{\text {loss }}+\lambda_{L}\left(1 / V S I_{\text {min }}\right)\right)
$$

where $F_{c}$ is the cost of the entire power system generation and it can be expressed as follows.

$$
F_{c}=\sum_{i=1}^{N_{g}} a_{i} P_{g i}^{2}+b_{i} P_{g i}+c_{i}(/ h)
$$

In this equation, $P_{g i}$ is the real power produced by the $i$ th generator; $a_{i}, b_{i}$ and $c_{i}$ are the fuel cost coefficients of the $i$ th generator; $N_{g}$ is the number of generators in the 


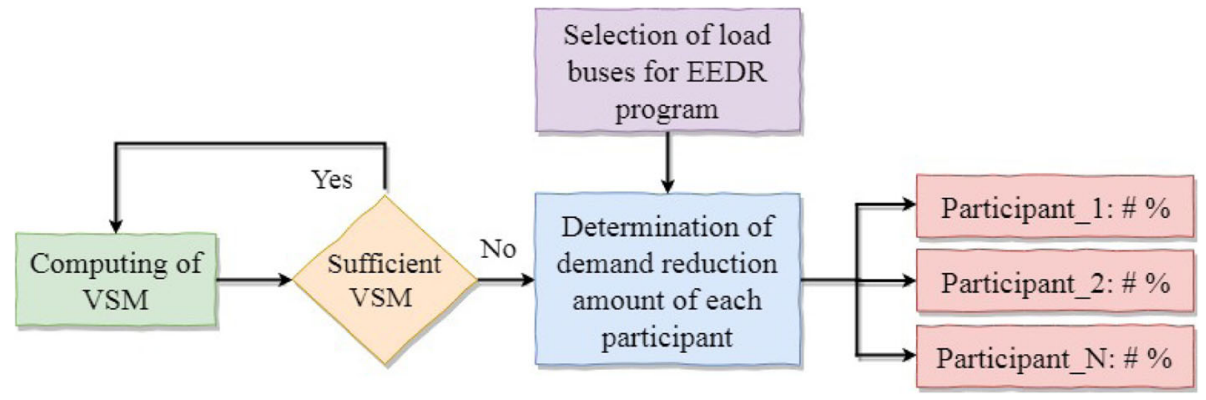

Fig. 5 Framework of the proposed EEDR strategy

system; $\lambda_{P}$ and $\lambda_{L}$ are scaling factors to balance between the objective function values and to avoid the dominance of an objective over another. The values of this factors are chosen as 40 and 100, respectively, same as in [41].

$P_{\text {loss }}$ represents the real power losses and it is given by the following equation.

$$
P_{\text {loss }}=\sum_{i=1}^{N_{b}} \sum_{j=1, j \neq i}^{N_{b}}\left[V_{i}^{2}+V_{j}^{2}-2 V_{i} V_{j} \cos \left(\theta_{i}-\theta_{j}\right)\right] Y_{i j} \cos \phi_{i j}
$$

where $\mathrm{N}_{\mathrm{b}}$ is the number of transmission lines; $\mathrm{V}_{\mathrm{i}}, \mathrm{V}_{\mathrm{j}}, \theta_{\mathrm{i}}$ and $\theta_{j}$ are the voltage magnitudes and the phase angles of the ith and jth buses, respectively; $Y_{i j}$ and $\phi_{i j}$ are the magnitudes and the phase angles of the lines admittance, respectively.

VSI $_{\text {min }}$ is the minimum value of Voltage Stability Index (VSI) [42]. This index is one of the most suitable indices due to its mathematical formulation which is derived considering all of the system margins (real, reactive and apparent power margins) [43]. This index is formulated as follows [42]:

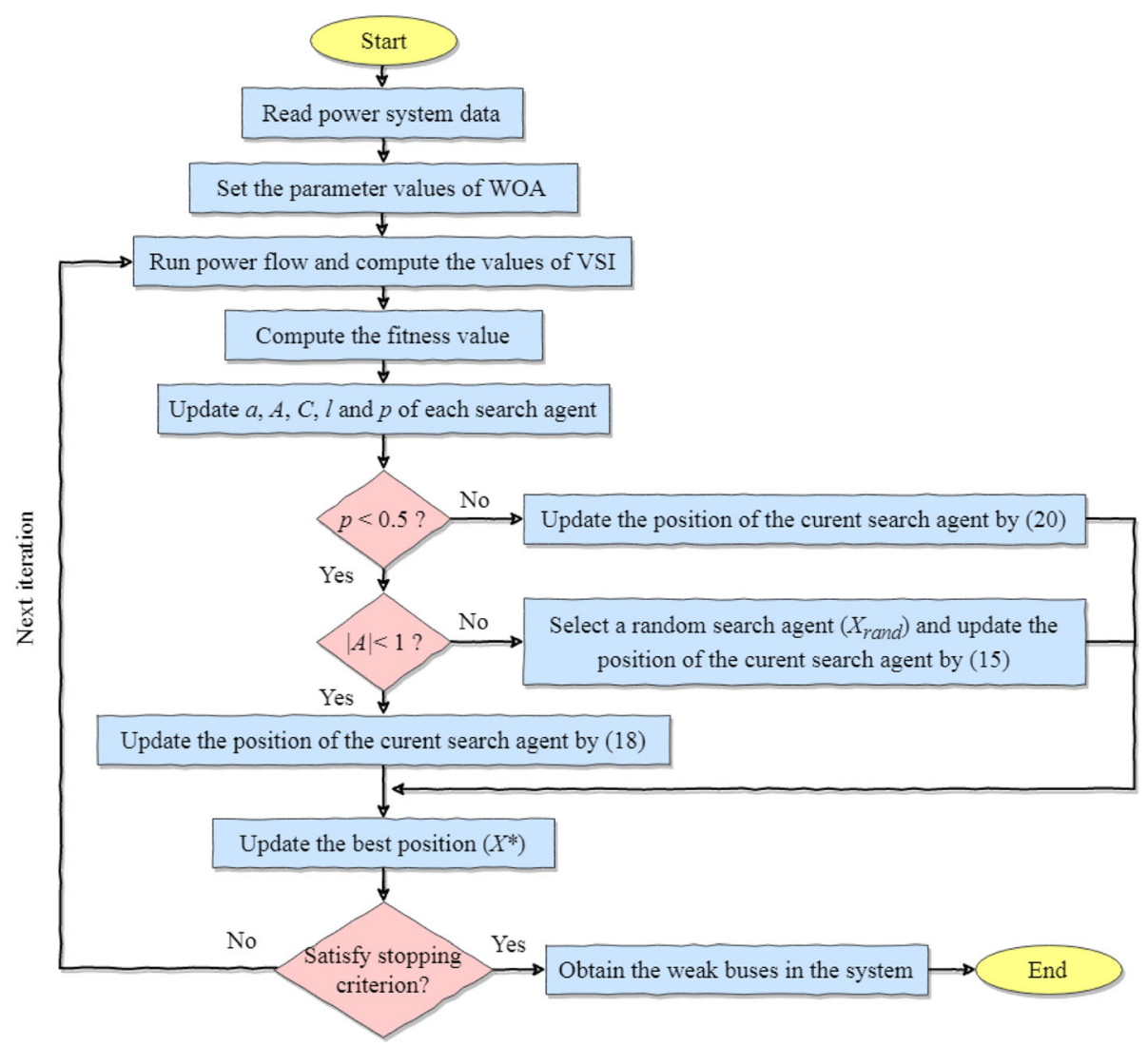

Fig. 6 General procedure of WOA-based weak buses identification methodology 


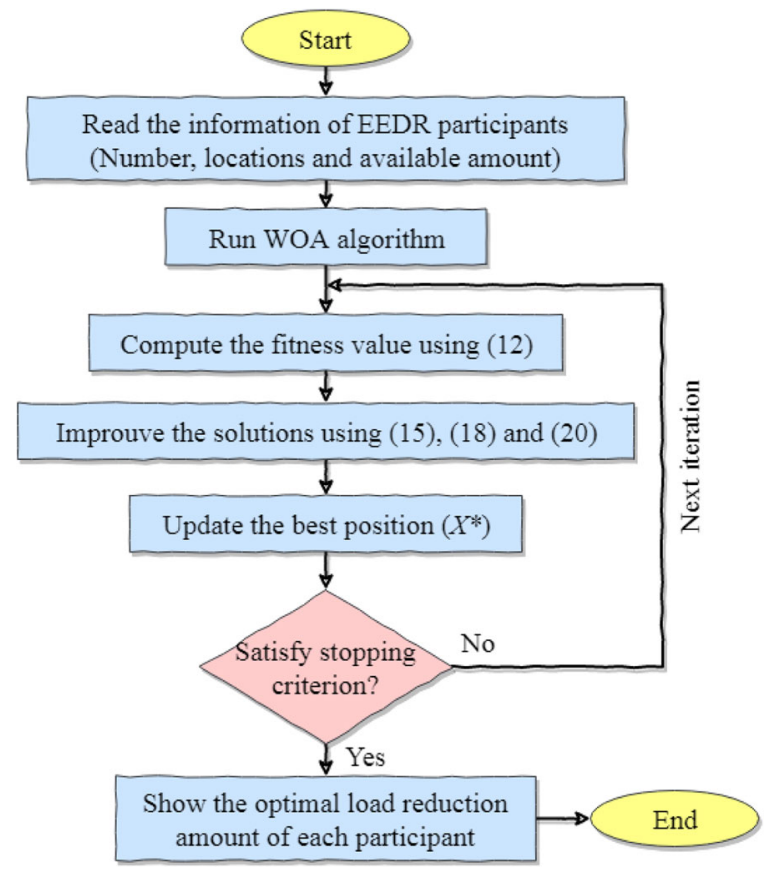

Fig. 7 Flowchart illustrating the process of demand reduction amount optimization using WOA

$$
V S I=\min \left(\frac{P_{\max }-P_{r}}{P_{\max }}, \frac{Q_{\max }-Q_{r}}{Q_{\max }}, \frac{S_{\max }-S_{r}}{S_{\max }}\right)
$$

Where

$$
P_{\max }=\sqrt{\frac{V_{s}^{4}}{4 X}-Q_{r} \frac{V_{s}^{2}}{X}}
$$

$$
\begin{aligned}
& Q_{\max }=\frac{V_{s}^{2}}{4 X}-\frac{P_{r}^{2} X}{V_{s}^{2}} \\
& S_{\max }=\frac{(1-\sin (\theta)) V_{s}^{2}}{2 \cos (\theta)^{2} X}
\end{aligned}
$$

where $P_{\max }, Q_{\max }$, and $S_{\max }$ are, respectively, the maximum transferred real, reactive and apparent powers; $\mathrm{V}_{\mathrm{s}}$ and $V_{r}$ are, respectively, the sending and the receiving end voltages; $X$ is the line reactance; $\theta$ is the load power angle.

By using VSI, stability level of all the transmission lines can be measured and the line with the minimum value of VSI $\left(\mathrm{VSI}_{\text {min }}\right)$ is considered as the most sensitive line to the voltage collapse $[44,45]$.

The objective function in (1) is subject to the equality and inequality constraints described by the following equations.

Equality constraints: The equality constraints represent the load flow equations, which are given below:

$$
\begin{gathered}
P_{g i}-P_{d i}-V_{i} \sum_{j=1}^{N_{b u s}} V_{j}\left(g_{i j} \cos \delta_{i j}+b_{i j} \sin \delta_{i j}\right)=0 \\
Q_{g i}-Q_{d i}-V_{i} \sum_{j=1}^{N_{b u s}} V_{j}\left(g_{i j} \sin \delta_{i j}-b_{i j} \cos \delta_{i j}\right)=0
\end{gathered}
$$

Inequality constraints: represents generator, load bus and transmission line constraints as given below:

Generator constraints:

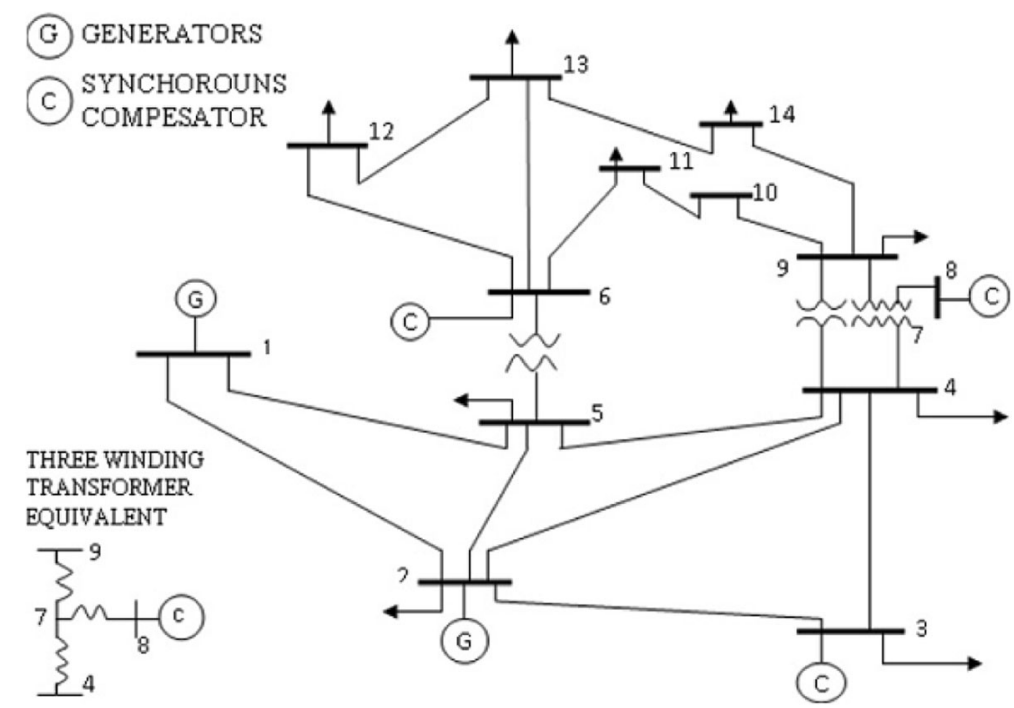

Fig. 8 Single line diagram of the IEEE 14-bus test system 


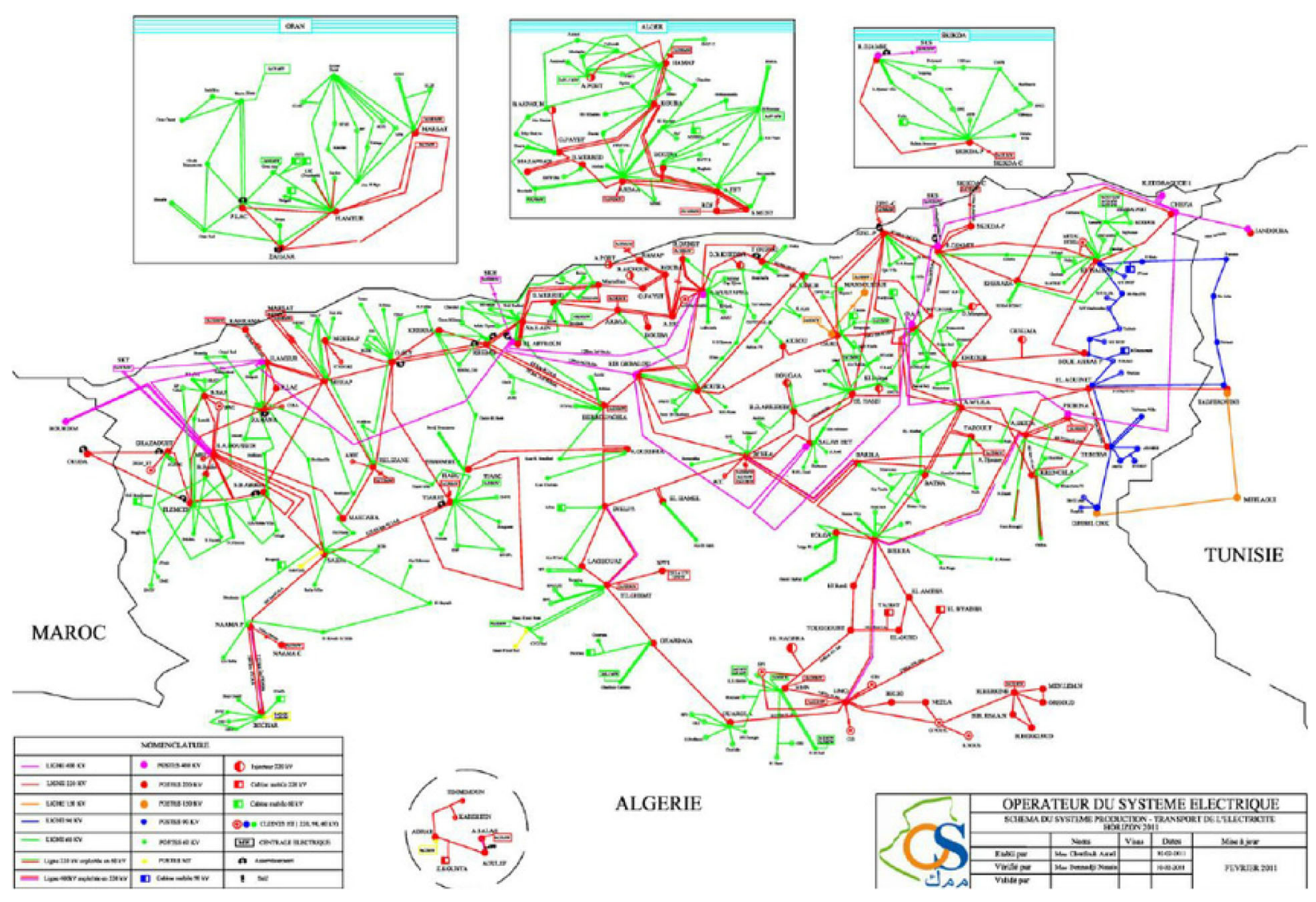

Fig. 9 Topology of the Algerian 114-bus power system [45]

$$
\begin{gathered}
V_{g i}^{\min } \leq V_{g i} \leq V_{g i}^{\max }, \\
\left\{P_{g i}^{\min } \leq P_{g i} \leq P_{g i}^{\max },\right.
\end{gathered}
$$

Load bus constraints:

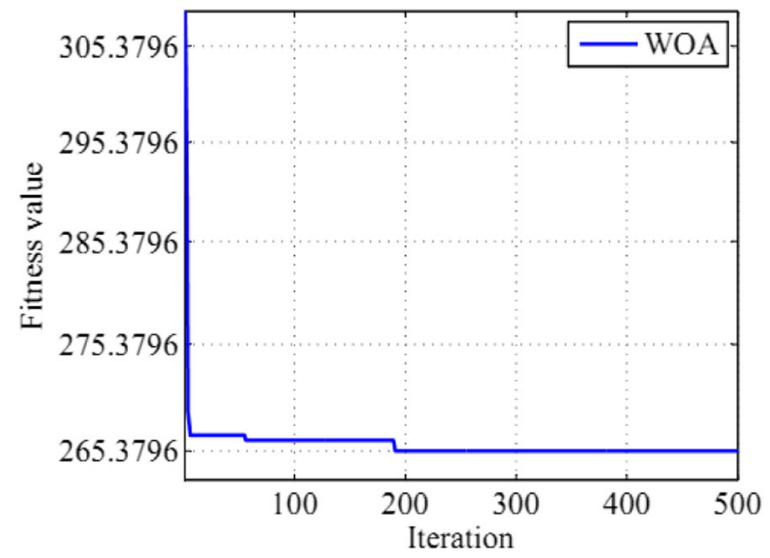

Fig. 10 Convergence characteristic of WOA in the case of IEEE 14-bus

$$
V_{l i}^{\min } \leq V_{l i} \leq V_{l i}^{\max }, \quad i=1,2, \ldots, N_{l b}
$$

Transmission line constraints:

$$
S_{l i} \leq S_{l i}^{\max }, \quad i=1,2, \ldots, N_{b}
$$

where $N_{\text {bus }}$ is the number of buses; $N_{g}$ is the number of generator buses; $P_{d i}$ and $Q_{d i}$ are the real and reactive load on the $i$ th bus, respectively; $g_{i j}, b_{i j}$ and $\delta_{i j}$ are, respectively, the conductance, the admittance and the phase difference of voltages between the $i$ th and $j$ th bus. $V_{g i}{ }^{\text {min }}$ and $V_{g i}{ }^{\text {max }}$ are the minimum and maximum voltage limits; $V_{l i}$ is the load voltage of $i$ th load bus; $S_{l i}$ is the apparent power flow of $i$ th branch and $N_{l b}$ is the number of load buses.

Table 1 Comparison of two approaches of EEDR (IEEE 14-bus)

\begin{tabular}{lllll}
\hline Method & Location & $\begin{array}{l}\text { Amount } \\
(\%)\end{array}$ & $\begin{array}{l}\text { Total } \\
\text { amount }\end{array}$ & $\begin{array}{l}\text { Total cost } \\
{[\$ / \mathrm{hr}]}\end{array}$ \\
\hline Multistage method & 14 & 30 & $14.22 \mathrm{MW}$, & 822.0 \\
{$[40]$} & 9 & 30 & $7.06 \mathrm{MVAr}$ & \\
& 10 & 10 & & \\
WOA algorithm & 4 & 11 & 14.6817 & 265.2326 \\
& 5 & 0 & MW, & \\
& 7 & 0 & 2.3305 & \\
& 14 & 6 & MVAr & \\
& 9 & 9 & & \\
\hline
\end{tabular}


Table 2 Set of the critical contingencies of IEEE 14-bus and Algerian 114-bus systems

\begin{tabular}{llll}
\hline Power system & Contingency $N^{\circ}$ & Line outage & VSI \\
\hline IEEE 14-bus & 1 & $1-2$ & 0.0381 \\
& 2 & $2-3$ & 0.6468 \\
& 3 & $5-6$ & 0.6753 \\
Algerian 114-bus & 4 & $7-9$ & 0.6857 \\
& 5 & $4-7$ & 0.7057 \\
& Intact condition & - & 0.7573 \\
& 1 & $63-66$ & 0.1261 \\
& 2 & $81-90$ & 0.1720 \\
& 3 & $85-87$ & 0.2438 \\
& 5 & $81-82$ & 0.2950 \\
& 5 & $87-100$ & 0.3359 \\
& Intact condition & - & 0.3674 \\
\hline
\end{tabular}

\subsection{Determination of demand reduction amount}

During emergency situations, emergency demand response coordinates many large energy consumers (e.g., large commercial and industrial sectors) for demand reduction. For each critical event, it must minimize the amount of demand reduction of each participant to the achieve a desired security margin with a minimum cost of demand reduction. These requirements lead to a nonlinear optimization problem in which the optimization goal is to minimize the demand reduction cost and the constraint is that the voltage stability margin of the power system after the demand reduction must be larger or equal to the desired one. Other constraints, such as power flow equations and safety operation constraints are also considered. Combining the objective function and all these constraints, the nonlinear optimization problem can be defined as presented below.

$$
\min \sum_{i=1}^{m} C_{i}
$$

Subjected to the following constraints:

- Power system constraints described by (8-15);

- Available amounts of demand participants;

- Voltage stability margin. where $C_{i}$ is the cost for reducing demand at load bus $i$; $m$ is the number of available participants.

The cost for reducing demand is represented as follows [40]:

$$
C_{i}=50+5\left(\frac{\Delta S_{i}}{S_{i}}\right)^{2}, \quad i=1,2,3, \ldots, m
$$

where $S_{i}$ and $\Delta S_{i}$ are, respectively, the load and the total load reduction at the selected location $i$. The unit-price for each load is assumed to be $50 \$ / \mathrm{hr}$. at the base case and changes with a second-order polynomial function as shown in (13).

\section{Proposed EEDR-based WOA algorithm}

\subsection{Basic principles of WOA algorithm}

Whale Optimization Algorithm (WOA) is a novel bioinspired optimization technique proposed by Mirjalili and Lewis [46]. It is based on the simulation of the special hunting method of one of the biggest baleen whales called humpback whales. Humpback whales feed a small prey as krill, herrings, and other small fishes near the surface, their demeanour to find and hunt the prey is called "bubble-net feeding". The humpback whales dive down and then start to create a ring of bubbles to encircle the fishes, which are too frightened to pass through the bubbles as shown in Fig. 1, in meantime the whales swim upward to the surface through the bubble net and swallowing a huge number of fishes in one swig. Bubblenet feeding behaviour is mathematically modelled as follows.

\subsection{Searching for prey}

Humpback whales search for prey randomly according to the position of each other. The process of searching is mathematically modelled as follows:

$$
\begin{aligned}
& D=\left|C . X_{\text {rand }}-X\right| \\
& X(t+1)=X_{\text {rand }}-A . D
\end{aligned}
$$

where $t$ indicates the current iteration, $X$ is the position

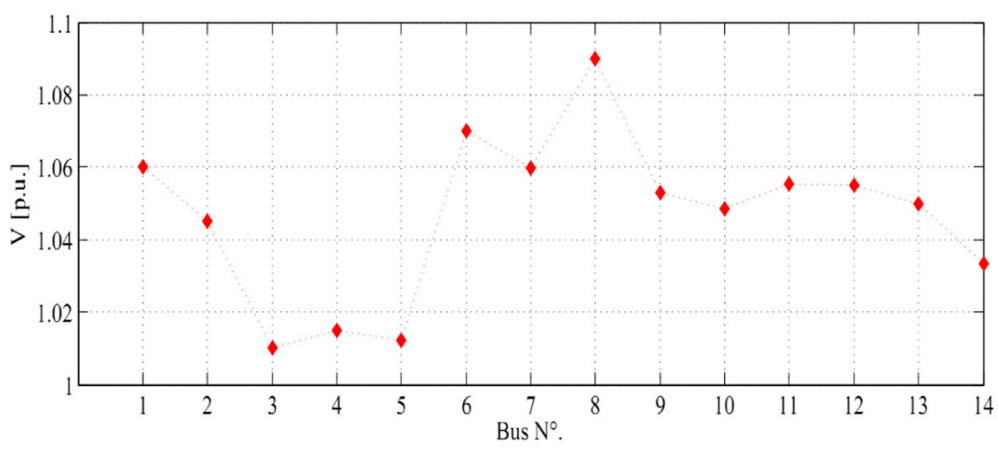

Fig. 11 Voltage profiles in the case of loss of line (1-2) in the IEEE 14-bu system 


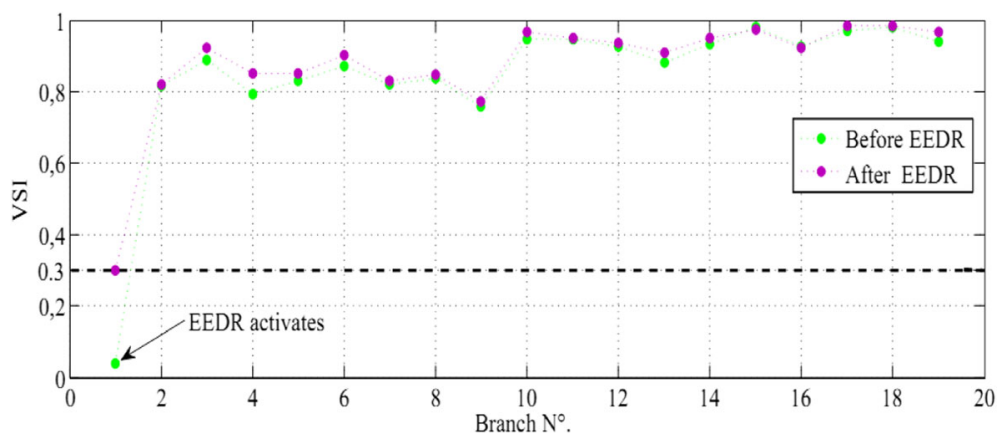

Fig. 12 VSI before and after EEDR in the case of loss of line (1-2) in the IEEE 14-bus system

vector, $X_{\text {rand }}$ is a random position vector (a random whale) chosen from the current population. $A$ and $C$ are coefficient vectors calculated as follows:

$$
\begin{aligned}
& A=2 a \cdot r-a \\
& C=2 r
\end{aligned}
$$

where $\mathrm{a}$ is linearly decremented from 2 to 0 along with the iterations, $\mathrm{r}$ is a random vector in $[0,1]$. Therefore, $A$ is used with the random values $|\mathrm{A}|>1$ in order to guarantee the global search for the WOA algorithm. The position of every search agent (whale) is updated based on the random selection of search agent [46].

\subsection{Prey encircling technique}

After locating the prey, humpback whales circle this prey to start hunting them. The WOA presumes that the actual best candidate solution is the target prey or is close to the optimum. Accordingly, the overall search agents will renew their new positions towards the bestdetermined search agent. This demeanour is represented as follows:

$$
D=|C . X *(t)-X(t)|
$$

$$
X(t+1)=X *(t)-A . D
$$

where $X^{*}$ is the position vector of the best solution obtained so far. Figure 2 illustrates the rationale behind (19). The position $(X, Y)$ of a search agent can be updated, according to the position of the current best record $\left(X^{*}, Y^{*}\right)$, by adjusting the values of $A$ and $C$ vectors.

\subsection{Bubble-net attacking technique}

As aforementioned above, after locating the prey and encircling them, humpback whales start the hunting step using the bubble-net mechanism. Two approaches to model the bubble-net demeanor of humpback whales are proposed. The first one is the shrinking encircling technique. This behavior is achieved by decrementing the value of $a$ in (16), consequently, the value of $A$ is also decreased by $a$. Figure 3 shows the possible positions from $(X, Y)$ towards $\left(X^{*}, Y^{*}\right)$ that can be achieved by $0 \leq \mathrm{A} \leq 1$. The second one is the spiral updating position. In this approach the distance between the whale located at $(X, Y)$ and the prey located at $\left(X^{*}, Y^{*}\right)$ is first calculated (see Fig. 4), then the spiral equation to imi-

\begin{tabular}{|c|c|c|c|c|c|c|c|}
\hline \multirow[t]{2}{*}{ System } & \multirow[t]{2}{*}{ Events } & \multirow[t]{2}{*}{ Location } & \multirow{2}{*}{$\begin{array}{l}\text { Amount } \\
(\%)\end{array}$} & \multirow{2}{*}{$\begin{array}{l}\text { Total } \\
\text { amount }\end{array}$} & \multirow{2}{*}{$\begin{array}{l}\text { Total } \\
\text { cost } \\
{[\$ / \mathrm{hr}]}\end{array}$} & \multicolumn{2}{|l|}{ VSI } \\
\hline & & & & & & Before EEDR & After EEDR \\
\hline IEEE 14-bus & Loss of the line $(1-2)$ & $\begin{array}{l}4 \\
5 \\
7 \\
14 \\
9\end{array}$ & $\begin{array}{l}47 \\
14 \\
4 \\
15 \\
35\end{array}$ & $\begin{array}{l}21.4330 \mathrm{MW} \\
3.6351 \mathrm{MVAr}\end{array}$ & 446.8791 & 0.0381 & 0.3004 \\
\hline \multirow[t]{2}{*}{ Algerian 114-bus } & Loss of the line (63-66) & $\begin{array}{l}89 \\
68 \\
92 \\
67\end{array}$ & $\begin{array}{l}4 \\
45 \\
2 \\
69\end{array}$ & $\begin{array}{l}\text { 6.3631 MW, } \\
\text { 3.0578 MVAr }\end{array}$ & 550.5759 & 0.1261 & 0.3000 \\
\hline & Loss of the line $(81-90)$ & $\begin{array}{l}89 \\
68 \\
92 \\
67\end{array}$ & $\begin{array}{l}41 \\
0 \\
2 \\
0\end{array}$ & $\begin{array}{l}\text { 8.4208 MW, } \\
\text { 4.2103 MVAr }\end{array}$ & 287.5827 & 0.1720 & 0.3001 \\
\hline
\end{tabular}
tate the helix-shaped movement of humpback whales is formed as follows:

Table 3 EEDR results in IEEE 14-bus and Algerian 114-bus systems in the case of line tripping 


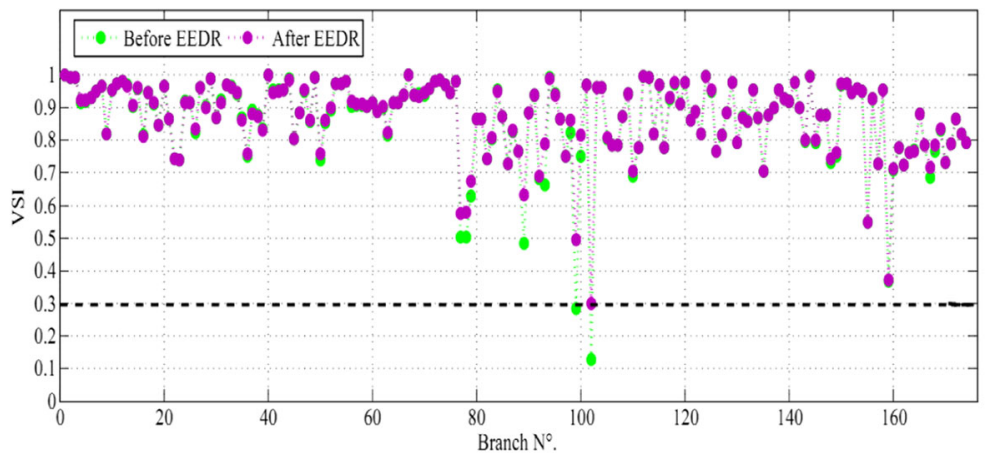

(a)

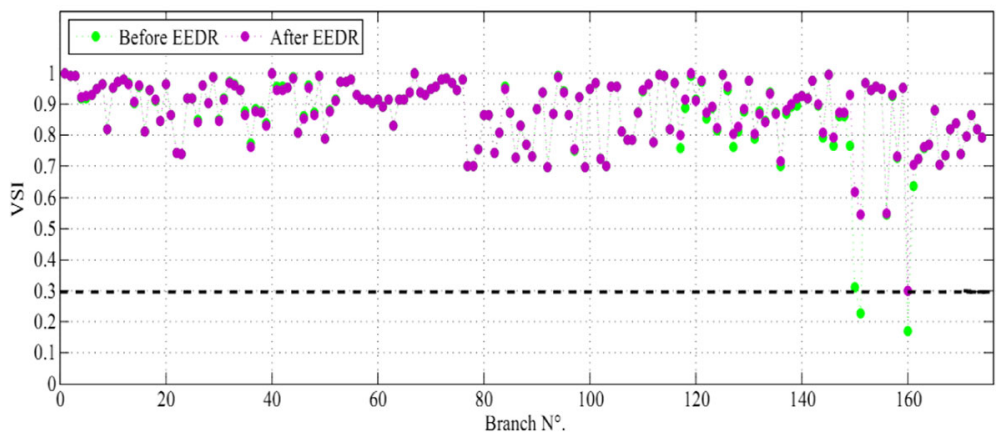

(b)

Fig. $13 \mathrm{VSI}$ of the Algerian 114-bus system in the case of (a) loss of line (63-66), (b) loss of line (81-90)

$$
X(t+1)=D^{\prime} \cdot e^{b l} \cdot \cos (2 \pi l)+X *(t)
$$

Where:

$$
D^{\prime}=\left|X^{*}(t)-X(t)\right|
$$

$D^{\prime}$ indicates the distance between the $i$ th whale and the prey (best solution obtained so far), $b$ is a constant that determines the form of the logarithmic spiral, $l$ is a randomly chosen number in the range $[-1,1]$. The humpback whales swim around the prey within a

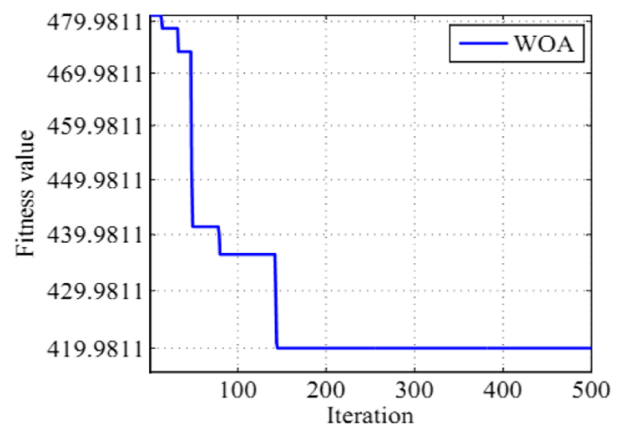

(a) shrinking circle and along a spiral path at the same time. To model this simultaneous behavior, we suppose that there is a probability of $50 \%$ to choose the technique that will be used to update the position of whales during optimization. The mathematical model is as follows:

$$
X(t+1)=\left\{\begin{array}{l}
X *(t)-A \cdot D \quad \text { if } p<0.5 \\
D^{\prime} \cdot e^{b l} \cdot \cos (2 \pi l)+X *(t) \quad \text { if } p \geq 0.5
\end{array}\right.
$$

\subsection{Implementation of WOA in EEDR program}

In this sub-section, we discussed the detailed procedure to apply WOA based method in EEDR program. The

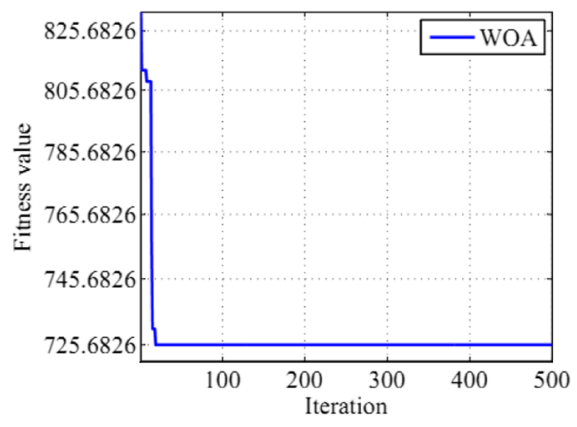

(b)

Fig. 14 Convergence characteristic of WOA in the IEEE 14-bus system, increasing of load by: (a) 170\%, (b) 190\% 


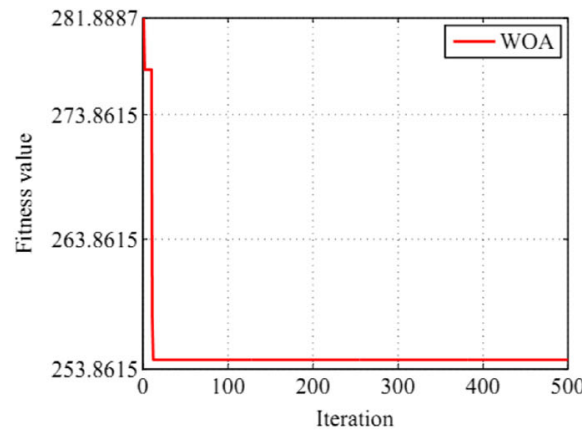

(a)

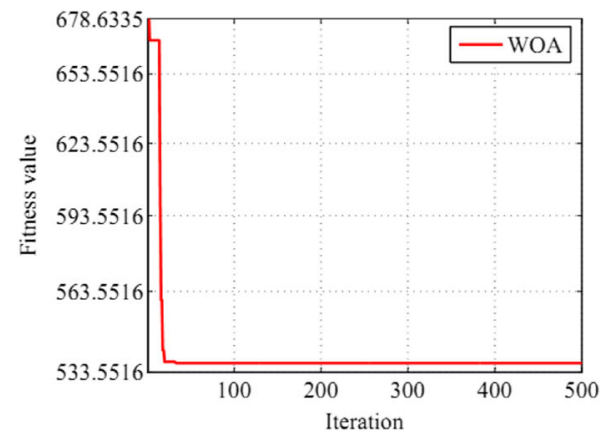

(b)

Fig. 15 Convergence characteristic of WOA in the Algerian 114-bus system, increasing of load by: (a) 20\%, (b) 35\%

proposed EEDR strategy has the objective to maintain the voltage stability margin (VSM) in an acceptable range and it activates when VSM leaves their permitted ranges during the emergency conditions caused by critical contingencies. The framework of the proposed strategy is shown in Fig. 5 with the following three main steps:

(a) Computation of VSM.

(b) Selection of suitable load buses for EEDR program.

(c) Determination of demand reduction amount of each participant.

The first step involves the calculation of the VSI defined by (4). By computing this voltage stability index, we can estimate the VSM of the system and thereby convenient countermeasure may be taken if the index indicates a poor VSM. In the second step, WOA optimization algorithm is used to solve the problem of determination of suitable locations for load reduction represented by (1). Assuming that all the load buses in the power system can participate in the EEDR program, the procedure used to find the appropriate locations, using WOA algorithm, is summarized in the flowchart of Fig. 6. In the third step, the WOA algorithm is adopted to seek for the amounts of load reduction of each participant in the EEDR program. The flowchart describing the process of demand reduction amount optimization using WOA optimization algorithm is shown in Fig. 7.

\section{Results and discussion}

In this section, the effectiveness of the proposed EEDR strategy has been validated on the IEEE 14-bus test

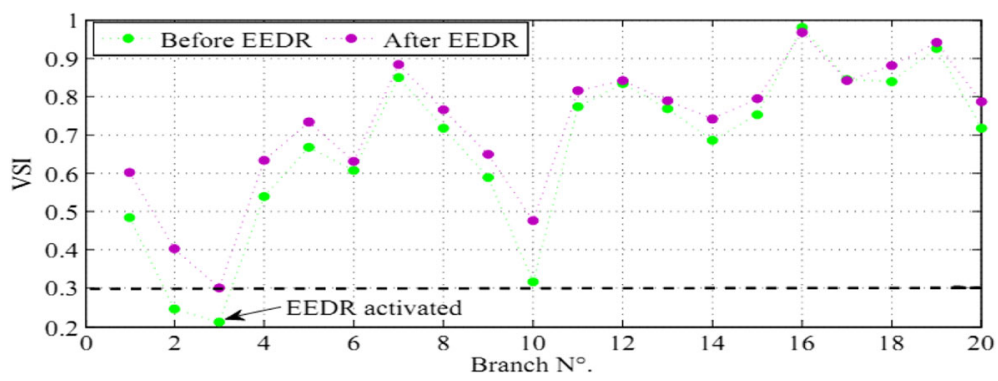

(a)

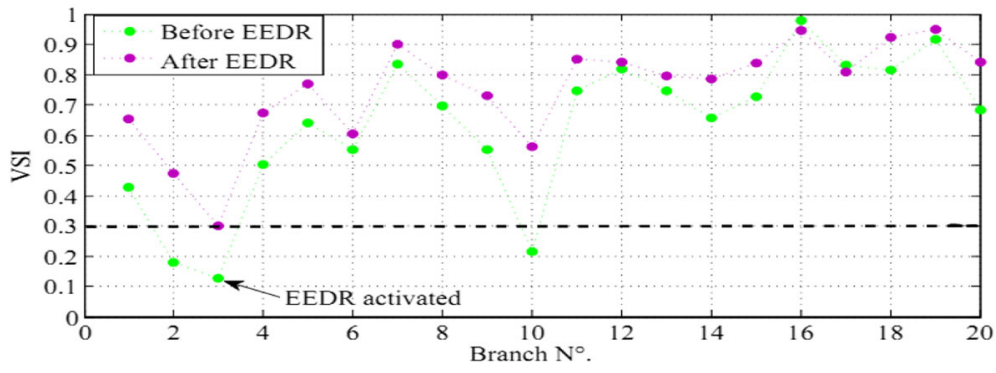

(b)

Fig. 16 VSI of the IEEE 14-bus system in the case of (a) increasing of load by 170\%, (b) increasing of load by $190 \%$ 


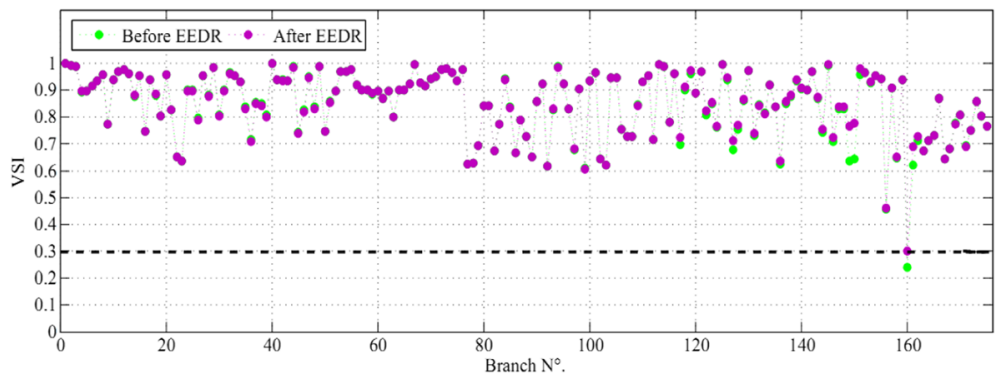

(a)

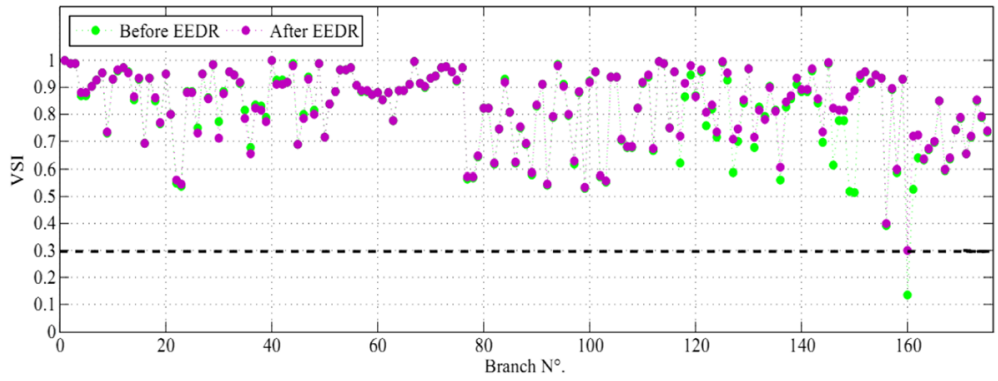

(b)

Fig. 17 VSI of the Algerian 114-bus system in the case of (a) increasing of load by 20\%, (b) increasing of load by $35 \%$

system [47] and the real Algerian 114-bus [48] power system. The IEEE 14-bus test system, shown in Fig. 8, consists of 14 buses, 5 generators, and 20 lines. The Algerian 114-bus system, shown in Fig. 9, contains 114 buses, 15 generators and 175 branches.

\subsection{Examples on line tripping}

Firstly, to validate the proposed EEDR approach, the same scenario with that of [40] has been simulated. In this operating scenario, the load demand of the IEEE 14bus system is increased by $85 \%$ from its base case operating state. After the occurrence of two lines outages (lines from bus 2 to bus 4 and from bus 2 to bus 5), insufficient VSM is detected. So the proposed strategy acts to ensure that the VSI is no less than 0.3. Using WOA algorithm, the buses 4, 5, 7, 14 and 9 are identified to be the most sensitive buses in the case of IEEE 14-bus system. These buses are taken as the appropriate locations

Table 4 EEDR results in IEEE 14-bus and Algerian 114-bus systems in the case of load increasing

\begin{tabular}{|c|c|c|c|c|c|c|c|}
\hline \multirow[t]{2}{*}{ System } & \multirow[t]{2}{*}{ Events } & \multirow[t]{2}{*}{ Location } & \multirow{2}{*}{$\begin{array}{l}\text { Amount } \\
(\%)\end{array}$} & \multirow[t]{2}{*}{ Total amount } & \multirow{2}{*}{$\begin{array}{l}\text { Total } \\
\text { cost } \\
{[\$ / h r]}\end{array}$} & \multicolumn{2}{|l|}{ VSI } \\
\hline & & & & & & Before EEDR & After EEDR \\
\hline \multirow[t]{2}{*}{ IEEE 14-bus } & Increasing of load by $170 \%$ & $\begin{array}{l}4 \\
5 \\
7 \\
14 \\
9\end{array}$ & $\begin{array}{l}43 \\
29 \\
9 \\
10 \\
21\end{array}$ & $\begin{array}{l}\text { 52.6923 MW, } \\
\text { 6.9592 MVAr }\end{array}$ & 419.9811 & 0.2109 & 0.3 \\
\hline & Increasing of load by $190 \%$ & $\begin{array}{l}4 \\
5 \\
7 \\
14 \\
9\end{array}$ & $\begin{array}{l}68 \\
26 \\
21 \\
15 \\
59\end{array}$ & $\begin{array}{l}\text { 60.6080 MW, } \\
\text { 11.9255 MVAr }\end{array}$ & 725.6826 & 0.1261 & 0.3001 \\
\hline \multirow[t]{2}{*}{ Algerian 114-bus } & Increasing of load by $20 \%$ & $\begin{array}{l}89 \\
68 \\
92 \\
67\end{array}$ & $\begin{array}{l}32 \\
0 \\
0 \\
0\end{array}$ & $\begin{array}{l}\text { 8.8781 MW, } \\
\text { 4.4390 MVAr }\end{array}$ & 254.5213 & 0.2390 & 0.3011 \\
\hline & Increasing of load by $35 \%$ & $\begin{array}{l}89 \\
68 \\
92 \\
67\end{array}$ & $\begin{array}{l}69 \\
0 \\
42 \\
2\end{array}$ & $\begin{array}{l}\text { 13.2722 MW, } \\
\text { 6.6361 MVAr }\end{array}$ & 536.7319 & 0.1376 & 0.3 \\
\hline
\end{tabular}


for EEDR. The convergence curve of WOA algorithm searching for the optimal load reduction at the selected buses is shown in Fig. 10.

Table 1 shows the EEDR results obtained using the WOA algorithm and those obtained by using the multistage optimization strategies [40]. As shown in this Table, the real and reactive powers of load buses 4, 5, 7, 14 and 9 are reduced by $11 \%, 0 \%, 0 \%, 6 \%$, and $9 \%$, respectively. It is also evident from this table that better results are obtained suing EEDR-based WOA algorithm.

To confirm the effectiveness of the proposed EEDR strategy, some further events have been simulated. Firstly, the line connecting the buses 1 and 2 in the IEEE 14-bus system was tripped. The loss of this line is considered as the most severe contingency as shown in Table 2. During this contingency, the voltage magnitudes at all buses are within the predetermined voltage limits as shown in Fig. 11. However, the lowest value of VSI $\left(V S I_{\text {min }}\right)$ drops below the constraint of 0.3. This would indicate that the corresponding line is closed to its voltage stability limit and the control strategy will be activated accordingly as shown in Fig. 12. After the application of EEDR-based WOA, it is seen that the VSM is enhanced. The obtained EEDR results are summarized in Table 3. The 4th column of this Table indicates the obtained amount of load reduction for each participant. The 5th and 6th columns show the total amount and the cost of load reduction, respectively. Columns 7 and 8 show, respectively, the minimum values of VSI before and after the application of EEDR-based WOA. It can be seen from this Table that the total reduction cost when the line $1-2$ is tripped is 446.8791 $[\$ / \mathrm{h}]$, the total real and reactive powers required to avoid a risk of voltage collapse are $21.433 \mathrm{MW}$ and 3.6351 MVAr, respectively.

The breadth of the study was expanded by performing another test on the Algerian 114-bus power system. The selected load buses, using WOA algorithm, were the buses 89, 68, 92 and 67. To perform the tests, two deferent branch outage contingencies were chosen from Table 2 . The first one is the loss of the line between buses 63 and 66 where the minimum value of VSI was 0.1261 . The second contingency is the outage of the branch between buses 81 and 90 where the minimum value of VSI was 0.1720 . This low VSIs violation activates the proposed EEDR. Figure 13(a) and (b) represent the Algerian power system VSIs, concerning each event, before and after the application of the proposed EEDR-based WOA method. As can be expected, before the application of EEDR the system has an insecure VSM due to the line outage contingencies. However, after the application of EEDR the $\mathrm{VSI}_{\text {min }}$ successfully increased to 0.3 for the two events enlarging the VSM. We can observe also from the Fig. 13 that VSM of the whole system is improved. The detailed
EEDR results for the above two cases are also summarized in Table 3. It appears from these results that the proposed EEDR strategy works satisfactorily in the case of line outage contingencies.

\subsection{Examples on load increase}

The second scenario demonstrates the performance of the proposed strategy for the load increase. Thus, all loads in the IEEE 14-bus system are increased by $170 \%$ and $190 \%$ from its initial load level. Similarly, all loads in the Algerian 114-bus power system are increased by $20 \%$ and $35 \%$. In these cases, the predicted values of VSI for both test systems are less than the threshold level of 0.3 . This means that the systems have a great possibility of voltage collapse without any remedial actions. Since insufficient VSM $\left(\mathrm{VSI}_{\min }<0.3\right)$ is detected, the EEDRbased WOA strategy will be activated accordingly. Figures 14 and 15 show the convergence curves of WOA algorithm seeking for the optimal load reduction at the selected buses in both test systems. After the application of the proposed EEDR, the VSI violations have been eliminated effectively as shown in Figs. 16 and 17. In all the above-mentioned cases, the reduction in the load power demand is distributed among the participants as shown in Table 4. The results depicted in Figs. 16 and 17 and Table 4 demonstrate the effectiveness of the proposed EEDR-based WOA method in the improvement of the VSM.

\section{Conclusions}

In this paper, an event-driven emergency demand response (EEDR) based on whale optimization algorithm (WOA) is proposed to improve the voltage stability of power system as well to avoid a risk of voltage collapse. In the proposed approach, the voltage stability margin (VSM) is, firstly, computed using the voltage stability index. Then, the WOA is adopted to seek for the optimal locations and amounts of load reduction of each participant in the EEDR program. The simulation results carried out using the IEEE 14-bus and the Algerian 114bus power system proved the potential of the proposed EEDR scheme in the restoration of the power system from the emergency operating conditions. On the other hand, the use of the proposed strategy, to reach the desired VSM, results in lower demand reduction costs compared to other methods in the literature.

\section{Methods section}

This paper aims to propose an event-driven emergency demand response (EEDR) to effectively improve system voltage stability. The main objective of the proposed EEDR approach is to maintain the Voltage Stability Margin (VSM) in an acceptable range during emergency conditions by driving the operating condition of a power 
system away from the insecure points. VSM is determined by computing voltage stability index (VSI) using load flow equations. The identification of the best locations for EEDR participant is mathematically formulated as a non-linear constrained optimization problem, where the main goal is the determination of the optimal location for reactive power support. The determination of the optimal load reduction amount for each participant in the EEDR program, to achieve the desired VSM with the minimum cost of demand reduction, is also formulated as a non-linear optimization problem. For optimization, the recently proposed whale optimization algorithm (WOA) is used. Computer programs are written, using MATLAB software, from which the optimal locations and load reduction amounts are obtained and the results are compared.

\section{Acknowledgements}

Not applicable.

\section{Author's contributions}

MA carried out problem formulation, simulation, preparing manuscript, TB and IM supervised this research work, participated in the development of the proposed methodology and helped to draft the manuscript. All authors read and approved the final version of the manuscript.

\section{Funding}

Not applicable.

\section{Availability of data and materials}

Not applicable.

\section{Competing interests}

The authors declare that they have no competing interests.

\section{Author details}

'Department of Electrical Engineering, University of Ferhat Abbas Setif 1, 19000 Setif, Algeria. ${ }^{2}$ Faculty of Electrical Engineering, Universiti Teknologi MARA, 40450 Shah Alam, Malaysia.

\section{Received: 22 September 2018 Accepted: 8 November 2019}

\section{References}

1. Bo, Z., Shaojie, O., Jianhua, Z., Hui, S., Geng, W., \& Ming, Z. (2015). An analysis of previous blackouts in the world: Lessons for China's power industry. Renew Sust Energ Rev, 42, 1151-1163.

2. Vournas, D., \& Manos, A. (2001). Emergency tap-blocking to prevent voltage collapse. Porto, Portugal: In IEEE Power Tech. Conf.

3. Otomega, B., Sermanson, V., \& Van Cutsem, T. (2003). Reverse-logic controlof load tap changers in emergency voltage conditions. Bologna, Italy: In IEEE Power Tech. Conf.

4. Vournas, C., \& Karystianos, M. (2004). Load tap changers in emergency and preventive voltage stability control. IEEE Trans Power Syst, 19(1), 492-498.

5. Barboza, L., Lerm, A., \& Salgado, R. (2005). Load shedding - an efficient use of LTC transformers. In 15th Power System Computation Conference (PSCC 2005 LIEGE), Liège, Belgium (pp. 289-295).

6. Ashwani Kumar, S., Srivastava, S., \& Singh, A. (2004). Zonal congestion management approach using real and reactive power rescheduling. IEEE Trans Power Syst, 19(1), 554-562.

7. Talukdar, B., Sinha, A., \& Mukhopadhyay, S. (2005). A computationally simple method for cost-efficient generation rescheduling and load shedding for congestion management. Int. J. Electr Power Energy Syst, 77, 379-388.

8. Yesuratnam, G., \& Thukaram, D. (2007). Congestion management in open access based on relative electrical distances using voltage stability criteria. Elect Power Syst Res, 77, 1608-1618.
9. Dutta, S., \& Singh, S. (2008). Optimal rescheduling of generator for congestion management based on particle swarm optimization. IEEE Trans Power Syst, 23(4), 1560-1569.

10. Chakrabarti, S., \& Jeyasurya, B. (2008). Generation rescheduling using ANNbased computation of parameter sensitivities of the voltage stability margin. Eng Appl Artif Intell, 21(8), 1164-1169.

11. Raouf, H., \& Kalantar, M. (2009). Reactive power rescheduling with generator ranking for voltage stability improvement. Energy Convers Manag, 50(4), 1129-1135.

12. Rajalakshmy, S., \& Jasmy, P. (2015). Voltage stability by reactive power rescheduling using PSO algorithm. Proc Comput Sci, 46, 1377-1384.

13. Sumit, V., \& Vivekananda, M. (2016). Optimal real power rescheduling of generators for congestion management using a novel ant lion optimiser. IET Generation, Transm Distrib, 10(10), 2548-2561.

14. Sadhan, G., Arup, G., Prashant, T., \& Subhasish, D. (2016). Rescheduling of real power for congestion management with integration of pumped storage hydro unit using firefly algorithm. Electr Power Energy Syst, 83, 434442.

15. Jeslin, J., Drusila, P., Venkatesh, S., \& Charles, R. (2016). Energy management by generator rescheduling in congestive deregulated power system. Appl Energy, 171, 357-371.

16. Laghari, J., Mokhlis, H., Bakar, A., \& Hasmaini, M. (2013). Application of computational intelligence techniques for load shedding in power systems: A review. Energy Convers Manag, 75, 130-140.

17. Ardiaty, A., Yang, Z., Muhammad, B., \& Marcus, G. (2013). Under voltage load shedding in power systems with wind turbine-driven doubly fed induction generators. Electr Power Syst Res, 96, 91-100.

18. Tang, J., Liu, J., Ponci, F., \& Monti, A. (2013). Adaptive load shedding based on combined frequency and voltage stability assessment using synchrophasor measurements. IEEE Trans Power Syst, 28, 2035-2047.

19. Mousa, M., Maziar, M., Mudathir, F., \& Ghazal, K. (2016). Adaptive load shedding scheme for frequency stability enhancement in microgrids. Electr Power Syst Res, 140, 78-86.

20. Hsu, C., Kang, M., \& Chen, C. (2005). Design of adaptive load shedding by artificial neural networks. IET Gener Transm Dis, 15(2), 415-421.

21. Hooshmand, R., \& Moazzami, M. (2012). Optimal design of adaptive under frequency load shedding using artificial neural networks in isolated power system. Electr Power Energy Syst, 42, 220-228.

22. Haidar, A., Mohamed, A., Al-Dabbagh, M., \& Hussain, A. (2008). Vulnerability assessment and control of large-scale interconnected power systems usingneural networks and neuro-fuzzy techniques. In 2008 Australasian Universities Power Engineering Conference. Sydney, Australia.

23. Haidar, A., Mohamed, A., \& Hussain, A. (2010). Vulnerability control of large scale interconnected power system using neuro-fuzzy load shedding approach. Exp Syst App, 37(3), 171-176.

24. Bikas, A., Voumvoulakis, E., \& Hatziargyriou, N. (2009). Neuro-fuzzy decisiontrees for dynamic security control of power systems. In 15th International Conference on Intelligent System Applications to Power Systems (ISAP 2009). Curitiba, Brazil. (pp. 232-237).

25. Luan, W., Irving, M., \& Daniel, J. (2002). Genetic algorithm for supply restoration and optimal load shedding in power system distribution networks. IET Gener Transm Dis, 149, 145-151.

26. Arya, L., Singh, P., \& Titar, L. (2012). Optimum load shedding based on sensitivity to enhance static voltage stability using DE. Swarm Evol Comput, 6 , 25-38.

27. Mageshvaran, R., \& Jayabarathi, T. (2015). GSO based optimization of steadystate load shedding in power systems to mitigate blackout during generation contingencies. Ain Shams Eng J, 6, 145-160.

28. Mageshvaran, R., \& Jayabarathi, T. (2015). Steady-state load shedding to mitigate blackout in power systems using an improved harmony search algorithm. Ain Shams Eng J, 6, 819-834.

29. Ketabi, A., \& Hajiakbari, M. (2017). Adaptive under-frequency load shedding using particle swarm optimization algorithm. J Appl Res Technol, 15, 54-60

30. Sadati, N., Amraee, T., \& Ranibar, A. (2017). Global particle swarm-basedsimulated annealing optimization technique for under-voltage load shedding problem. Appl Soft Comput, 9, 652-657.

31. Nikolaos, G., Erdinç, O., \& João, P. (2017). An overview of demand response: Key-elements and international experience. Renew Sust Energ Rev, 69, 871-891.

32. Jamshid, A., Mohammad-Iman, A., Pierluigi, S., \& Alireza, H. (2016). Contribution of emergency demand response programs in power system reliability. Energy, 103, 688-696. 
33. Yousefi, A., Shayesteh, E., Zare, K., Jalal, K., Moghaddam, M., \& Haghifam, M. (2008). Risk-based spinning reserve allocation considering emergency demand response program. In 2008 43rd International Universities Power Engineering Conference (UPEC). Padova, Italy. (pp. 160-164).

34. Shayesteh, E., Yousefi, A., Parsa, M., \& Sheikh-EL-Eslami, M. (2009). ATC enhancement using emergency demand response program. Seattle, USA: In IEEE/PESPower System Conference and Exposition. (pp. 1395-1401).

35. Rajesh, T., \& Jason, W. (2010). Emergency demand response for distribution system contingencies. New Orleans, USA: In IEEE/PES Transmission and Distribution Conference and Exposition (T\&D 2010).(pp. 922-925).

36. Sahebi, M., Duki, E., Kia, A., \& Soroudi, M. (2012). Simultaneous emergency demand response programming and unit commitment programming in comparison with interruptible load contracts. IET Gener Transm Distrib, 6(7) 605-611.

37. Rahmani-Andebili, M., Abdollahi, A., Parsa, M., \& Moghaddam, M. (2011). An investigation of implementing emergency demand response program (EDRP) in unit commitment problem. Detroit, USA: In IEEE Power and Energy Society General Meeting.

38. Aalami, A., \& Khatibzadeh, A. (2016). Regulation of market clearing price based on nonlinear models of demand bidding and emergency demand response programs. Int Trans Electr Energy Syst, 26(11), 2463-2478.

39. Aghaei, J., Alizadeh, M., Siano, P., \& Heidari, A. (2016). Contribution of emergency demand response programs in power system reliability. Energy, 103, 688-696.

40. Wang, Y., Iraj, P., \& Wilson, X. (2011). An event-driven demand response scheme for power system security enhancement. IEEE Trans Smart Grid, 2(1), 23-29.

41. Mohamed, A., Mohamed, Y. S., El-Gaafary, A. A., \& Hemeida, A. M. (2017). Optimal power flow using moth swarm algorithm. Electr Power Syst Res, 142, 190-206.

42. Yanfeng, G., Schulz, N., \& Guzman, A. (2006). Synchrophasor-based real-time voltage stability index. Atlanta, USA: In IEEE/PES Power Systems Conference and Exposition(PSCE '06).

43. Salehi, V., \&Ossama, M. (2011). Real-time voltage stability monitoring and evaluation using Synchrophasor. Boston, USA: In IEEE North American Power Symposium (NAPS 2011). (pp. 260-266).

44. Adewole, A.C, \& Tzoneva, L. (2016). Extended synchrophasor-based online voltage stability assessment. International Transactions on Electrical Energy Systems, 27(1).

45. Chandraa, A., \& Pradhan, A. K. (2019). Online voltage stability and load margin assessment using wide area measurements. Electr Power Energy Syst, 108, 392-401.

46. Mirjalili, S., \& Lewis, A. (2016). The whale optimization algorithm. Adv Eng Softw, 95, 51-67.

47. Zimmerman, R.D., Murillo-Sánchez, C.E., \& Thomas, R.J. Matpower. http:// www.pserc.cornell.edu/matpower.

48. Slimani, L., \& Bouktir, T. (2012). Optimal power flow solution of the Algerian electrical network using differential evolution algorithm. Telkomnika, 10(2) 199-210.

\section{Submit your manuscript to a SpringerOpen ${ }^{\circ}$ journal and benefit from:}

- Convenient online submission

- Rigorous peer review

- Open access: articles freely available online

- High visibility within the field

- Retaining the copyright to your article

Submit your next manuscript at $\boldsymbol{\nabla}$ springeropen.com 